\title{
PRODUÇÃO DE METANO A PARTIR DO TRATAMENTO DE ESGOTO SANITÁRIO VISANDO ENERGIA ALTERNATIVA
}

\author{
Pedro Herlleyson Gonçalves Cardoso ${ }^{1}$ \\ Mauro Batista Sampaio ${ }^{2}$ \\ Edval Lavor Bezerra ${ }^{3}$ \\ Maria Aparecida Liberato Milhome ${ }^{4}$
}

\section{RESUMO}

Este estudo objetivou verificar a produção de metano em duas estações de tratamento de esgoto sanitário, compostas de reatores tipo UASB, no semiárido cearense. O processo no interior dos reatores consiste basicamente de um fluxo ascendente de esgotos por meio de um leito de lodo denso e de elevada atividade e com coleta do efluente na parte superior. No fundo do reator há a formação de um leito de lodo mais denso até um lodo mais disperso próximo ao topo do reator. A estabilização da matéria orgânica ocorre pela da passagem e mistura do esgoto no leito de lodo promovida pelo fluxo ascensional e das bolhas de gás formadas. Utilizou-se três reatores do tipo UASB, em escala real. Os resultados demonstraram que no reator 1 obteve eficiência de $94 \%$ de remoção de matéria orgânica em termos de DQO, sendo convertida $49,67 \mathrm{Kg} \mathrm{DQO} \mathrm{CH}_{4} /$ dia, alcançando uma quantidade máxima de metano de $19,30 \mathrm{~m}^{3} / \mathrm{dia}$ em um TDH de 17,5 horas, a uma temperatura operacional de $30^{\circ} \mathrm{C}$. Nos reatores 2 e 3 observou-se eficiência de $90 \%$ de remoção de matéria orgânica em termos de DQO, sendo convertida 295,30 Kg DQO $\mathrm{CH}_{4} /$ dia, obtendo uma quantidade máxima de metano de $115,11 \mathrm{~m}^{3} /$ dia em um TDH de 4,5 horas, a uma temperatura operacional de $31^{\circ} \mathrm{C}$. Neste contexto, pode-se concluir que os resultados alcançados indicaram um potencial significativo de produção de metano a partir da remoção da carga orgânica, com possibilidades de aproveitamento energético a partir de uma fonte renovável.

Palavras-chave: Reator UASB. Metano. Esgoto sanitário.

Recebido em: 08/07/2016 | Aceito em: 28/07/2016

\footnotetext{
${ }^{1}$ Mestre em Recursos Hídricos e Saneamento pela UFAL. Doutorando em Química e Biotecnologia pela UFAL. Professor da URCA Iguatu. Colaborador do SAAE Iguatu. E-mail:

pedroherlleyson@yahoo.com.br

${ }^{2}$ Mauro Batista Sampaio Biólogo pela UECE. Coordenador do Núcleo de Tratamento de Água e Esgoto do SAAE Iguatu. E-mail: pedro@saae.iguatu.ce.gov.br

${ }^{3}$ Graduado em Letras pela UECE. Superintendente do SAAE Iguatu. E-mail:

pedro@saae.iguatu.ce.gov.br

${ }^{4}$ Química pela UFC. Mestre e Doutora em Engenharia Civil (Saneamento) pela UFC. Professora do IFCE Campus Iguatu. E-mail: maria.milhome@nutec.ce.gov.br
}

Ciência e Sustentabilidade - CeS | Juazeiro do Norte v. 2, n. 1, p. 23-40, jan/jun 2016 I ISSN 2447-4606 


\section{INTRODUÇÃO}

O uso de tecnologias renováveis tem sido viabilizado devido à redução da disponibilidade de recursos naturais e o aumento da preocupação com o meio ambiente. Entretanto algumas técnicas ainda tornam-se inviáveis, devido aos elevados custos de implantação se comparados aos modelos adotados atualmente. Contudo, entre essas técnicas, um método se destaca devido ao elevado potencial energético e viabilidade econômica: o reaproveitamento do biogás proveniente de Estações de Tratamento de Esgotos (ETEs) (SOARES, 2011). No caso particular do Brasil, com o aumento da implantação de reatores e biodigestores anaeróbios para o tratamento de esgoto doméstico, é possível antever que a recuperação e o uso direto do biogás poderão ser bastante incrementados no futuro (LOBATO, 2011).

Neste contexto, tem-se o reator UASB que retêm biomassa através de um decantador localizado no topo do reator e os gases são separados por defletores localizados na base dos decantadores. Atualmente, é um dos reatores mais utilizados. Se destaca pela sua simplicidade e a não necessidade de material de enchimento. Foi um dos primeiros reatores a atingir altas taxas de aplicação de matéria orgânica

O biogás neste tipo de reator, origina-se no processo de transformação da matéria orgânica presente no afluente realizada pelas bactérias anaeróbias facultativas que residem no interior do reator UASB, esse processo ocorre em quatro etapas: hidrólise, acidogênese, acetogênese e metanogênese, etapa esta que o metano é produzido (SOARES, 2011). O biogás gerado em reatores anaeróbicos é composto basicamente por metano $\left(\mathrm{CH}_{4}\right)$, dióxido de carbono $\left(\mathrm{CO}_{2}\right)$, ácido sulfídrico $\left(\mathrm{H}_{2} \mathrm{~S}\right)$, hidrogênio $\left(\mathrm{H}_{2}\right)$ e amônia $\left(\mathrm{NH}_{3}\right)$. Sendo o metano o principal responsável por sua capacidade energética. A eficiência da estação de tratamento de esgoto, influenciado por fatores como: carga orgânica, pressão e temperatura durante a fermentação, faz com que o biogás contenha entre $40 \%$ e $80 \%$ de metano (COELHO et al., 2006).

No processo de conversão de matéria orgânica em condições de ausência de oxigênio são utilizados aceptores de elétrons inorgânicos como o NO ${ }^{3-}$ (redução de

Ciência e Sustentabilidade - CeS | Juazeiro do Norte v. 2, n. 1, p. 23-40, jan/jun 2016 
nitrato), $\mathrm{SO}_{4}{ }^{2-}$ (redução de sulfato), ou $\mathrm{CO}_{2}$ (formação de metano). A formação de metano não ocorre em ambientes onde o oxigênio, nitrato ou sulfato encontram-se prontamente disponíveis como aceptores de elétrons (GARCIA, 2009).

De acordo com o exposto, este estudo objetivou verificar a produção de metano em duas ETEs, compostas de reatores tipo UASB, que tratam esgoto sanitário no semiárido cearense.

\section{METODOLOGIA}

Tratamento Anaeróbio Utilizado

Realizou-se tratamento anaeróbio do esgoto sanitário por meio de três reatores anaeróbios de manta de lodo tipo UASB (Upflow Anaerobic Sludge Blanket). Os reatores, em escala real, foram fabricados em material Plástico Reforçado com Fibra de Vidro (PRFV). Atualmente os reatores são de responsabilidade de uma empresa que presta serviço na área de saneamento básico, localizada na região centro sul do Ceará.

Anteriormente do esgoto entrar nos reatores, o mesmo passa por um tratamento preliminar, que consiste em gradeamento para retenção de sólidos grosseiros e caixa de areia para remoção de areia. $O$ espaçamento entre barras do gradeamento é de 1" e a espessura das barras é de $3 / 8$ ".

No início do estudo, realizou-se descarga de lodo em excesso dos reatores para obter a concentração dos sólidos suspensos voláteis, visando a caracterização do mesmo e estimativa da quantidade de microorganimos ativos aptos a degradação da matéria orgânica.

\section{Características dos Reatores UASB}

Reator 1 - Possui $5 \mathrm{~m}$ de diâmetro, 5,2 $\mathrm{m}$ de altura total, sendo 4,5 m de altura útil, e volume de $88,31 \mathrm{~m}^{3}$. Existem 3 registros de amostras, que servem também para descarga do lodo excedente, situam-se a 0,20 m, 0,90 m e 1,90 m da base do reator. Este reator encontra-se instalado geograficamente a UTM 467.951 $\mathrm{mE}$ 9.296.021 mS. Trata o esgoto predominantemente sanitário proveniente de 117 Ciência e Sustentabilidade - CeS | Juazeiro do Norte v. 2, n. 1, p. 23-40, jan/jun 2016 
ligações derivadas do sistema de esgotamento sanitário de parte da cidade onde o mesmo está localizado, observado uma vazão média de contribuição de aproximadamente $88 \mathrm{~m}^{3}$ por dia. A Figura 1 ilustra o reator.

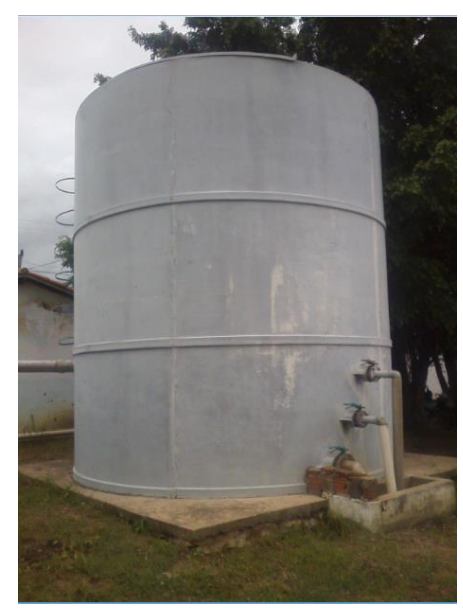

Figura 1: Vista do reator 1, em escala real.

Fonte: Acervo pessoal (2014).

Reator 2 e 3 - Possui 5,50 m de diâmetro, 5,2 $\mathrm{m}$ de altura total, sendo 4,5 m de altura útil, e volume de $107 \mathrm{~m}^{3}$. Existem 4 registros de amostras que situam-se a $0,90 \mathrm{~m}, 1,25 \mathrm{~m}, 1,65 \mathrm{~m}$ e 2,0 $\mathrm{m}$ da base do reator, além dos 4 registros para descarga de lodo excedente. Estes reatores encontram-se instalados geograficamente a UTM $464.921 \mathrm{mE} 9.298 .998 \mathrm{mS}$. Trata o esgoto predominantemente sanitário proveniente de 869 ligações derivadas do sistema de esgotamento sanitário de parte da cidade onde o mesmo está localizado, observado uma vazão média de contribuição de aproximadamente $676 \mathrm{~m}^{3}$ por dia. A Figura 2 ilustra os reatores.

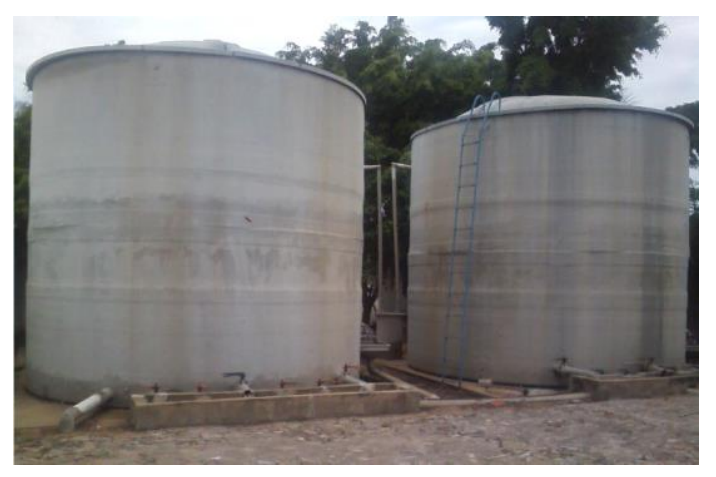

Figura 2 - Vista do reator 2 e 3, em escala real.

Fonte: Acervo pessoal (2014).

Ciência e Sustentabilidade - CeS | Juazeiro do Norte v. 2, n. 1, p. 23-40, jan/jun 2016 
Funcionamento Teórico dos Reatores UASB

O processo consiste basicamente de um fluxo ascendente de esgotos por meio de um leito de lodo denso e de elevada atividade e com coleta do efluente na parte superior do reator. No fundo do reator há a formação de um leito de lodo mais denso até um lodo mais disperso próximo ao topo do reator. A estabilização da matéria orgânica ocorre pela da passagem e mistura do esgoto no leito de lodo promovida pelo fluxo ascensional e das bolhas de gás formadas. A Figura 3 exibe a ilustração esquemática do reator.

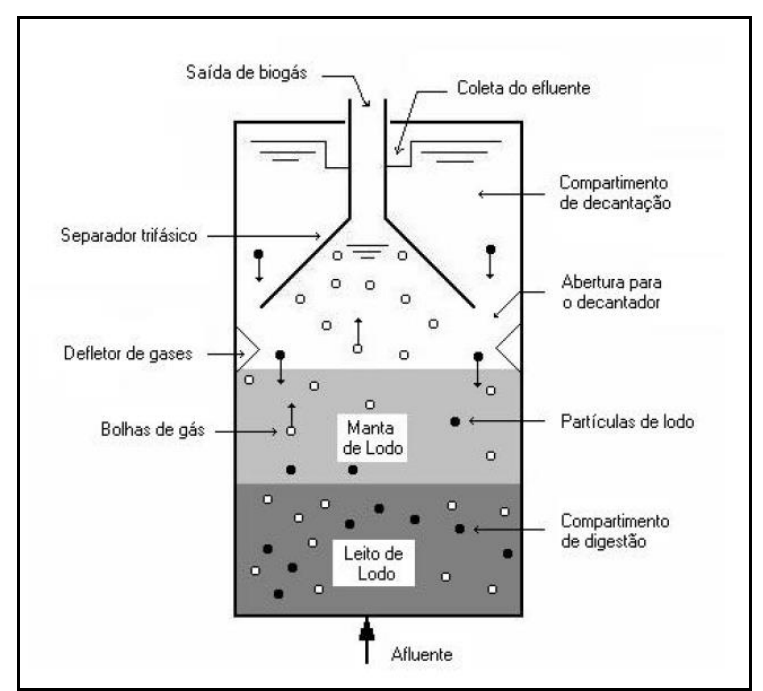

Figura 3: llustração esquemática do reator tipo UASB

Fonte: Chernicharo (2007).

O reator UASB, submetido a uma vazão de esgoto, passa a desenvolver, no seu interior, uma população de microorganismos adaptados às condições do meio $(\mathrm{pH}$, temperatura, substrato, carga hidráulica, etc) e evoluem formando grânulos, que são agregados de biomassa que ficam suspensos na massa líquida. A boa performance do reator UASB está diretamente relacionada a formação e desenvolvimento da granulação da biomassa de alta atividade, que será a responsável pela degradação da matéria orgânica do esgoto. Ao longo do perfil vertical do reator UASB, o lodo (constituído dos grânulos de agregados de biomassa) varia a sua concentração. No fundo é formado um lodo mais denso e com capacidade elevada de sedimentação (leito de lodo), variando, gradativamente, até 
um lodo mais leve e disperso no topo do reator (manta de lodo). O fluxo ascensional é o responsável por realizar a mistura de substrato com a biomassa e neste contato é que é promovida a estabilização da matéria orgânica ao longo do leito e da manta de lodo. Após a passagem pela zona de reação, o esgoto, por um mecanismo de separação de gases, encaminha os gases formados pelo processo (biogás) para o compartimento de saída de gases, onde é liberado na superfície da massa líquida. De outro lado, o esgoto, já sem os gases dissolvidos, são encaminhados para compartimentos de decantação. Neste compartimento de decantação o fundo tem uma inclinação onde os sólidos vão se depositando e, quando o peso dos flocos formados vencem a força de atrito, eles deslizarão encaminhando-se de volta ao compartimento de digestão (RISSOLI, 2014).

\section{Variáveis Analisadas}

A Tabela 1 descreve as características reacionais dos reatores na produção de metano.

Tabela 1 - Características operacionais em função do TDH para cada reator a ser estudado

\begin{tabular}{|c|c|c|c|c|c|c|c|}
\hline \multicolumn{8}{|c|}{ Características do Reator 1} \\
\hline & TDH & TDH & TDH & TDH & TDH & TDH & TDH \\
\hline & $29,7 \mathrm{~h}$ & $29,7 \mathrm{~h}$ & $59,4 \mathrm{~h}$ & $18,8 \mathrm{~h}$ & $14,5 \mathrm{~h}$ & $36,4 \mathrm{~h}$ & $17,5 \mathrm{~h}$ \\
\hline Vazão (m³/dia) & 47,58 & 47,58 & 23,59 & 75,34 & 97,54 & 38,86 & 80,89 \\
\hline $\begin{array}{c}\mathrm{CHV} \\
\left(\mathrm{m}^{3} / \mathrm{m}^{3} \cdot \mathrm{dia}\right)\end{array}$ & 0,54 & 0,54 & 0,27 & 0,85 & 1,10 & 0,44 & 0,92 \\
\hline $\mathrm{VA}(\mathrm{m} / \mathrm{h})$ & 0,10 & 0,10 & 0,05 & 0,16 & 0,21 & 0,08 & 0,17 \\
\hline \multicolumn{8}{|c|}{ Características dos Reatores 2 e 3} \\
\hline & $\mathrm{TDH}$ & TDH & TDH & TDH & TDH & TDH & TDH \\
\hline & $6,8 \mathrm{~h}$ & $5,4 \mathrm{~h}$ & $4,5 h$ & $4,9 h$ & $4,5 \mathrm{~h}$ & $7,4 \mathrm{~h}$ & $6,4 \mathrm{~h}$ \\
\hline Vazão (m³/dia) & 376,47 & 469,29 & 566,13 & 520,13 & 566,13 & 344,6 & 396,29 \\
\hline $\begin{array}{c}\mathrm{CHV} \\
\left(\mathrm{m}^{3} / \mathrm{m}^{3} \cdot \mathrm{dia}\right)\end{array}$ & 3,52 & 4,39 & 5,29 & 4,86 & 5,29 & 3,22 & 3,70 \\
\hline $\mathrm{VA}(\mathrm{m} / \mathrm{h})$ & 0,66 & 0,82 & 0,99 & 0,91 & 0,99 & 0,60 & 0,70 \\
\hline
\end{tabular}

TDH: Tempo de Detenção Hidráulico. CHV: Carga Hidráulica Volumétrica. VA: Velocidade Ascensional.

Ciência e Sustentabilidade - CeS | Juazeiro do Norte v. 2, n. 1, p. 23-40, jan/jun 2016 
Pedro Herlleyson Gonçalves Cardoso; Mauro Batista Sampaio; Edval Lavor Bezerra; Maria Aparecida Liberato Milhome

A Tabela 2 exibe as variáveis que foram analisadas ao longo do experimento para cada TDH analisado e seus respectivos métodos.

Tabela 2 - Variáveis analisadas ao longo do monitoramento dos reatores

\begin{tabular}{c|c|c}
\hline Variável & Unidade & Método \\
\hline $\mathrm{DQO}$ & $\mathrm{mg} / \mathrm{L}$ & Refluxação Fechada - Modificado - (5220 - B) \\
\hline $\mathrm{pH}$ & - & Eletrométrico (4500 - H+B) \\
\hline Temperatura & ${ }^{\circ} \mathrm{C}$ & Filamento de Mercúrio (2550 - A) \\
\hline
\end{tabular}

DQO: Demanda Química de Oxigênio. pH: Potencial Hidrogeniônico.

Realizou-se verificações de $\mathrm{pH}$, temperatura e DQO, visando monitorar a estabilidade operacional dos reatores, como também a taxa de conversão (remoção) de carga orgânica, visando relacionar com a produção de metano.

Produção Teórica de Metano nos Reatores UASB

Verificou-se a produção de metano segundo Chernicharo (2007) com base na Equação 1, onde teoricamente $64 \mathrm{~g}$ de DQO produzem $16 \mathrm{~g}$ de $\mathrm{CH}_{4}$. Nas CNTP 0,35 $\mathrm{L} \mathrm{CH}_{4} / \mathrm{g}$ DQO. A Equação 2 mostra a relação da produção teórica de metano por grama de DQO removida. A Equação 3 exibe como verificou-se o fator de correção de temperatura operacional. Verificou-se a produção teórica de metano nos reatores UASB segundo a frequência das verificações da variável DQO.

$\mathrm{CH}_{4}+2 \mathrm{O}_{2} \rightarrow \mathrm{CO}_{2}+2 \mathrm{H}_{2} \mathrm{O}$

$\mathrm{V}_{\mathrm{CH} 4}=\mathrm{DQO}_{\mathrm{CH} 4} / \mathrm{K}_{\mathrm{t}}$

Onde:

$\mathrm{V}_{\mathrm{CH} 4}=$ volume de $\mathrm{CH}_{4}$ produzido (L)

$\mathrm{DQO} \mathrm{cH}_{4}=\mathrm{DQO}$ removida ou convertida $\mathrm{a} \mathrm{CH}_{4}(\mathrm{gDQO})$

$\mathrm{K}_{\mathrm{t}}=$ fator de correção de temperatura operacional $(\mathrm{g} / \mathrm{DQO} / \mathrm{L})^{20}$

$K_{t}=\left(P^{*} K\right) / R(273+t)$

Onde:

Ciência e Sustentabilidade - CeS | Juazeiro do Norte v. 2, n. 1, p. 23-40, jan/jun 2016 
$\mathrm{P}=$ pressão atmosférica (1atm)

$\mathrm{K}=\mathrm{DQO}$ correspondente a $1 \mathrm{~mol}$ de $\mathrm{CH}_{4}\left(64 \mathrm{~g} \mathrm{DQO} / \mathrm{mol} \mathrm{CH}_{4}\right)$

$\mathrm{R}=$ constante de gases $\left(0,08206 \mathrm{~atm} . \mathrm{L} / \mathrm{mol} .{ }^{\circ} \mathrm{K}\right)$

$\mathrm{t}=$ temperatura operacional do reator $\left({ }^{\circ} \mathrm{C}\right)$

\section{RESULTADOS E DISCUSSÃO}

Verificando a estabilidade do reator 1 , observou-se que $\mathrm{o} \mathrm{pH}$ médio estabilizou-se em 7,09 $\pm 0,24$ na entrada do reator (afluente), e 7,18 $\pm 0,17$ na saída (efluente). A temperatura no reator 1 concentrou-se na faixa mesófila, verificando valores médios de $29,2^{\circ} \mathrm{C} \pm 0,9$ no afluente e $29,6^{\circ} \mathrm{C} \pm 0,8$ no efluente. A Tabela 3 detalha os valores de $\mathrm{pH}$ e temperatura verificados do reator 1 .

Tabela 3 - Valores de $\mathrm{pH}$ e temperatura verificados em campo do reator 1

\begin{tabular}{c|c|c|c|c}
\hline Valores & pH Afluente & pH Efluente & Temperatura Afluente $\left({ }^{\circ} \mathrm{C}\right)$ & Temperatura Efluente $\left({ }^{\circ} \mathrm{C}\right)$ \\
\hline Máximo & 7,45 & 7,45 & 30,0 & 31,0 \\
Mínimo & 6,77 & 6,98 & 28,0 & 28,5 \\
Média & 7,09 & 7,18 & 29,2 & 29,6 \\
Desvio Padrão & 0,24 & 0,17 & 0,9 & 0,8 \\
\hline
\end{tabular}

Verificando a estabilidade dos reatores 2 e 3 , observou-se que o pH médio estabilizou-se em 7,13 $\pm 0,16$ na entrada do reator (afluente), e 7,08 $\pm 0,23$ na saída (efluente). A temperatura nos reatores 2 e 3 concentrou-se na faixa mesófila, verificando valores médios de $30,6^{\circ} \mathrm{C} \pm 0,9$ no afluente e $31,1^{\circ} \mathrm{C} \pm 0,5$ no efluente. $A$ Tabela 4 detalha os valores de $\mathrm{pH}$ e temperatura verificados nos reatores 2 e 3 .

Tabela 4 - Valores de pH e temperatura verificados em campo dos reatores 2 e 3

\begin{tabular}{c|c|c|c|c}
\hline Valores & pH Afluente & pH Efluente & Temperatura Afluente $\left({ }^{\circ} \mathrm{C}\right)$ & Temperatura Efluente $\left({ }^{\circ} \mathrm{C}\right)$ \\
\hline Máximo & 7,28 & 7,39 & 32,0 & 32,0 \\
Mínimo & 6,84 & 6,83 & 29,0 & 30,5 \\
Média & 7,13 & 7,08 & 30,6 & 31,1 \\
Desvio Padrão & 0,16 & 0,23 & 0,9 & 0,5 \\
\hline
\end{tabular}

A Figura 4 ilustra o monitoramento dos dados de $\mathrm{pH}$ resultante afluente $\mathrm{e}$ efluente do reator 1 . Notou-se que no afluente, o mesmo variou de 6,77 a 7,45 e o Ciência e Sustentabilidade - CeS | Juazeiro do Norte v. 2, n. 1, p. 23-40, jan/jun 2016 
efluente obteve uma variação de 6,98 a 7,45. Pode-se dizer que não houve uma variação significativa, tratando-se dos valores verificados de $\mathrm{pH}$. A Figura 5 ilustra 0 monitoramento dos dados de $\mathrm{pH}$ resultante afluente e efluente dos reatores 2 e 3 . Notou-se que no afluente, o mesmo variou de 6,84 a 7,28 e o efluente obteve uma variação de 6,83 a 7,39. Pode-se dizer que não houve uma variação significativa, tratando-se dos valores verificados de $\mathrm{pH}$.

Estes valores demonstraram o bom tamponamento do sistema, o que contribuiu positivamente para o desenvolvimento de bactérias (CHERNICHARO, 2007).

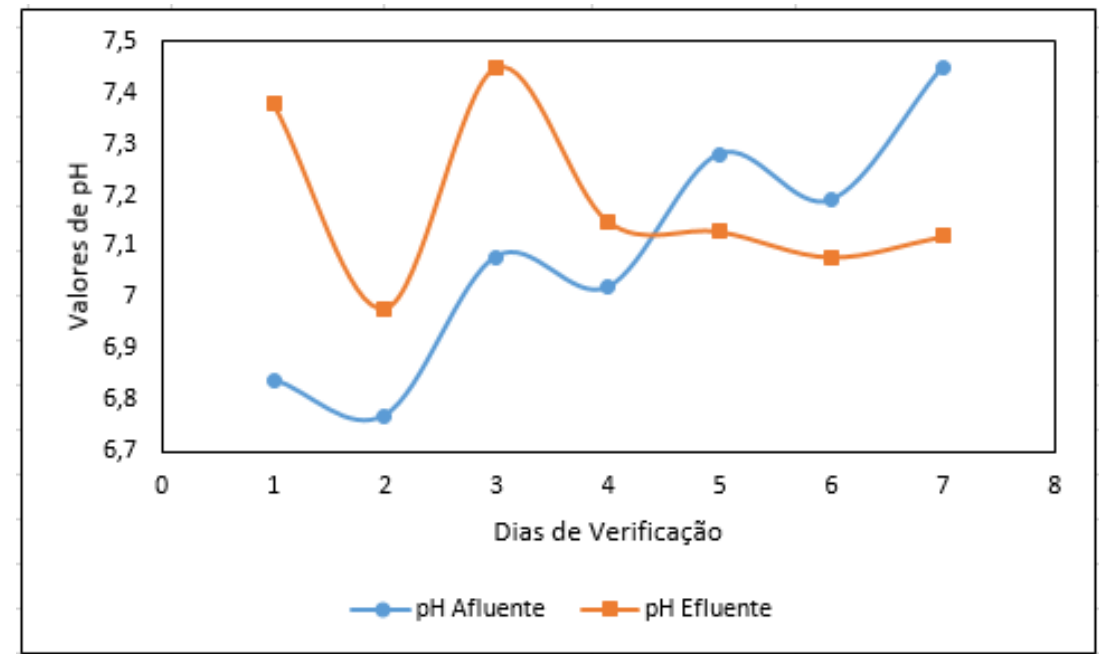

Figura 4 - llustração dos dados dos resultados de pH afluente e efluente do reator 1

Uma alta taxa de metanogênese ocorre somente quando o pH se mantém em uma faixa próxima do valor neutro. Por isso o controle do $\mathrm{pH}$ nos reatores anaeróbios é de estrema importância. Um pH menor que 6,3 ou maior que 7,8, provoca uma diminuição da taxa de metanogênese (VAN HAANDEL e LETTINGA, 1994). 


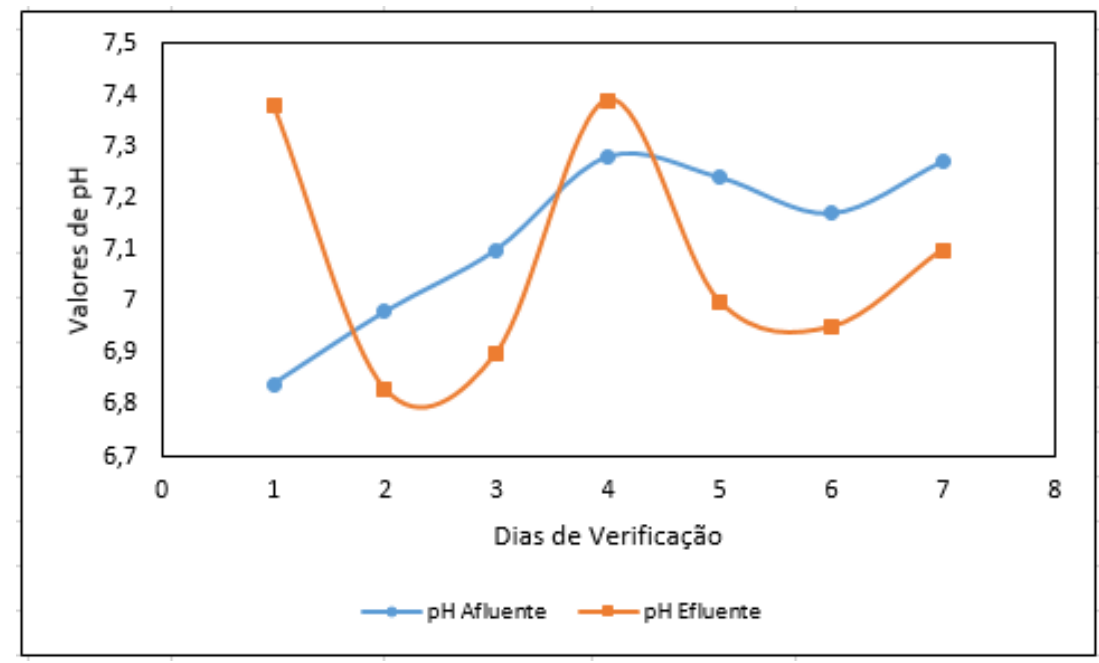

Figura 5 - llustração dos dados dos resultados de pH afluente e efluente dos reatores 2 e 3

A instabilidade no reator poderá acontecer se os ácidos produzidos na acidogênese não estiverem sendo removidos na metanogênese, ocasionando o chamado "azedamento" do reator, caracterizado pela elevada produção líquida de ácidos.

A Figura 6 mostra o monitoramento dos dados de temperatura afluente e efluente do reator 1 . Notou-se que no afluente, o mesmo variou de $28^{\circ} \mathrm{C}$ a $30^{\circ} \mathrm{C}$ e o efluente obteve uma variação de $28,5^{\circ} \mathrm{C}$ a $31^{\circ} \mathrm{C}$. A Figura 7 mostra o monitoramento dos dados de temperatura afluente e efluente dos reatores 2 e 3. Nestes, notou-se que no afluente variou de $29^{\circ} \mathrm{C}$ a $32^{\circ} \mathrm{C}$ e o efluente obteve uma variação de $30,5^{\circ} \mathrm{C}$ a $32^{\circ} \mathrm{C}$.

Pode-se dizer que nos três reatores analisados, assim como os valores de $\mathrm{pH}$, os dados de temperatura não houve uma variação significativa.

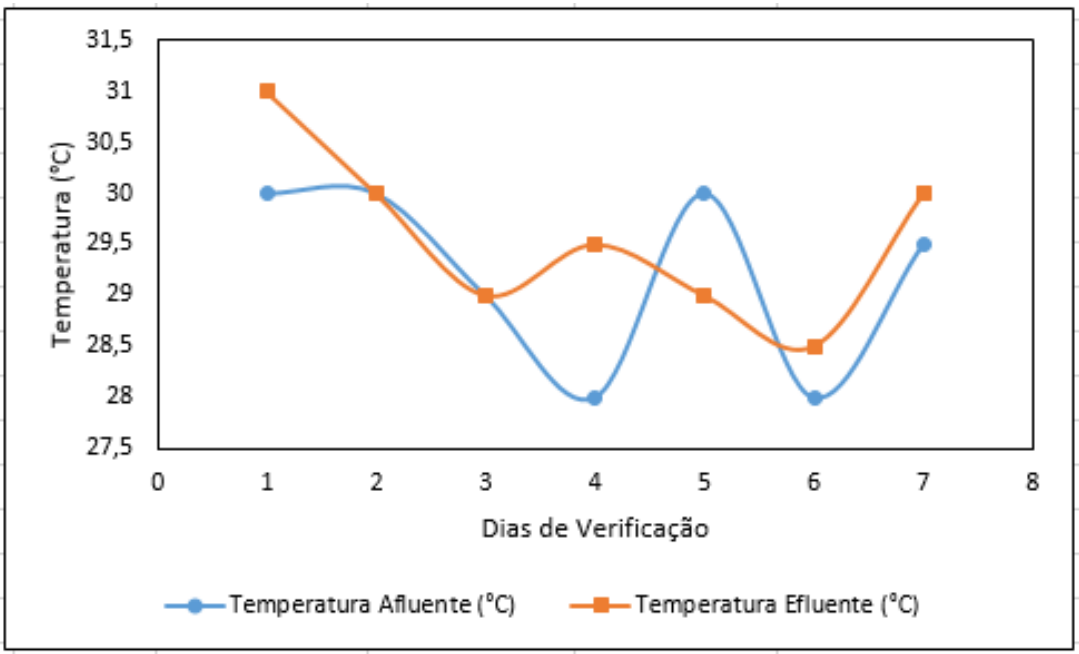

Ciência e Sustentabilidade - CeS | Juazeiro do Norte v. 2, n. 1, p. 23-40, jan/jun 2016 
Figura 6 - llustração dos dados dos resultados de temperatura afluente e efluente do reator 1

A digestão anaeróbia depende fortemente da temperatura, pois influencia a seleção das espécies que não possuem meios de controlar a temperatura interna. Três faixas de temperatura podem estar associadas à digestão anaeróbia, uma na faixa psicrófila $\left(0\right.$ a $\left.20^{\circ} \mathrm{C}\right)$ faixa mesófila $\left(20\right.$ a $\left.45^{\circ} \mathrm{C}\right)$ e a outra na faixa termófila (45 a $70^{\circ} \mathrm{C}$ ). A operação de reatores anaeróbios próximos à temperatura ótima pode levar a uma considerável redução nas dimensões do reator. No entanto, mudanças bruscas de temperatura podem levar a um desbalanceamento entre as bactérias acidogênicas e bactérias metanogênicas (CHERNICHARO, 2007).

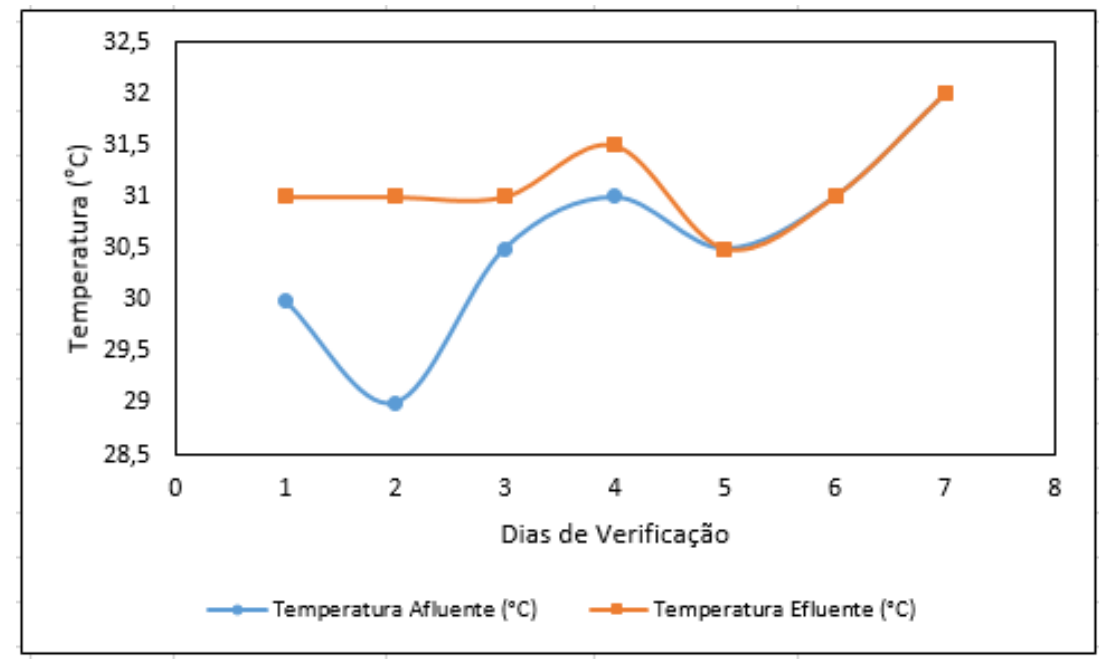

Figura 7 - llustração dos dados dos resultados de temperatura afluente e efluente dos reatores 2 e 3

Além de influenciar as taxas de digestão, a temperatura vai afetar a fração de sólidos orgânicos que podem ser metabolizados no processo de digestão anaeróbia. A fração digerida diminui consideravelmente com a temperatura, o que pode ser atribuída a uma baixa taxa de hidrólise, fazendo com que as grandes partículas sólidas não sejam quebradas. Apesar disso, é possível que o material orgânico particulado seja incorporado à manta de lodo através da adsorção, decantação ou floculação (VAN HAANDEL e LETTINGA, 1994).

No que diz respeito a carga inserida no reator 1 , pode-se verificar que houve uma variação na DQO afluente, observando uma amplitude de $300 \mathrm{mg} / \mathrm{L}$ a 906,25 $\mathrm{mg} / \mathrm{L}$, com as respectivas eficiências de remoção de $70 \%$ e $74 \%$. Verificou-se a maior eficiência quando inseriu-se $800 \mathrm{mg} \mathrm{DQO} / \mathrm{L}$ a uma temperatura operacional de Ciência e Sustentabilidade - CeS | Juazeiro do Norte v. 2, n. 1, p. 23-40, jan/jun 2016 
$30^{\circ} \mathrm{C}$, verificando a jusante $50 \mathrm{mg} \mathrm{DQO} / \mathrm{L}$. A Tabela 5 detalha todos os valores afluente e efluente experimentadas no reator 1 , seguido dos respectivos valores de temperatura operacional e eficiências de remoção no tocante a DQO.

Tabela 5 - Valores de DQO verificados em laboratório, temperatura operacional e porcentagem da eficiência de remoção do reator 1

\begin{tabular}{c|c|c|c}
\hline $\begin{array}{c}\text { Afluente } \\
(\mathrm{mg} \mathrm{DQO} / \mathrm{L})\end{array}$ & $\begin{array}{c}\text { Efluente } \\
(\mathrm{mg} \mathrm{DQO} / \mathrm{L})\end{array}$ & $\begin{array}{c}\text { Temperatura } \\
\left({ }^{\circ} \mathrm{C}\right)\end{array}$ & $\begin{array}{c}\text { Eficiência de remoção } \\
(\%)\end{array}$ \\
\hline 906,25 & 237,50 & 30 & 74 \\
843,75 & 156,25 & 30 & 81 \\
571,00 & 178,00 & 29 & 69 \\
625,00 & 165,00 & 29,5 & 74 \\
335,00 & 78,57 & 29 & 77 \\
300,00 & 89,57 & 28,5 & 70 \\
800,00 & 50,00 & 30 & 94 \\
\hline
\end{tabular}

No que diz respeito a carga inserida nos reatores 2 e 3, pode-se verificar que houve uma variação na DQO afluente, observando uma amplitude de 250,00 mg/L a $768,75 \mathrm{mg} / \mathrm{L}$, com as respectivas eficiências de remoção de 64\% e 69,11\%. Verificou-se a maior eficiência quando inseriu-se $714,00 \mathrm{mg} \mathrm{DQO} / \mathrm{L}$ a uma temperatura operacional de $31^{\circ} \mathrm{C}$, verificando a jusante $71,00 \mathrm{mg} \mathrm{DQO} / \mathrm{L}$. A Tabela 6 detalha todos os valores afluente e efluente experimentadas nos reatores 2 e 3 , seguido dos respectivos valores de temperatura operacional e eficiências de remoção no tocante a DQO.

Tabela 6 - Valores de DQO verificados em laboratório, temperatura operacional e porcentagem da eficiência de remoção dos reatores 2 e 3

\begin{tabular}{c|c|c|c}
\hline $\begin{array}{c}\text { Afluente } \\
(\mathrm{mg} \mathrm{DQO} / \mathrm{L})\end{array}$ & $\begin{array}{c}\text { Efluente } \\
(\mathrm{mg} \mathrm{DQO} / \mathrm{L})\end{array}$ & $\begin{array}{c}\text { Temperatura } \\
\left({ }^{\circ} \mathrm{C}\right)\end{array}$ & $\begin{array}{c}\text { Eficiência de remoção } \\
(\%)\end{array}$ \\
\hline 768,75 & 237,50 & 30 & 69,11 \\
750,00 & 250,00 & 31 & 66,67 \\
714,00 & 71,00 & 31 & 90,06 \\
700,00 & 108,00 & 31,5 & 84,57 \\
300,00 & 85,00 & 30,5 & 71,67 \\
250,00 & 90,00 & 31 & 64,00 \\
614,28 & 85,71 & 32 & 86,05 \\
\hline
\end{tabular}

Ciência e Sustentabilidade - CeS | Juazeiro do Norte v. 2, n. 1, p. 23-40, jan/jun 2016 
A Figura 8 exibe a variação de DQO afluente e efluente, e suas respectivas eficiências de remoção, no que diz respeito ao reator 1 . Notou-se que os valores de DQO efluente tenderam a uma estabilidade, ocorrência esta que difere dos valores de DQO afluente, observando uma diferença, fato este que deve-se a variabilidade das concentrações na entrada da estação de tratamento. Observou-se que não houve uma variação significante, tratando-se da eficiência do reator 1 .

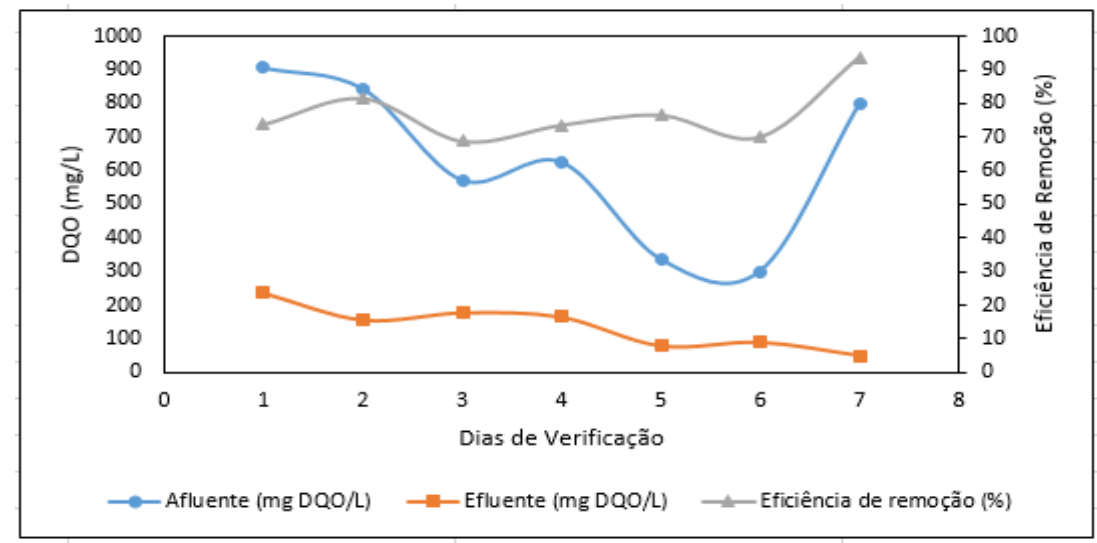

Figura 8 - llustração dos dados dos resultados de DQO afluente e efluente do reator 1

A Figura 9 exibe a variação de DQO afluente e efluente, e suas respectivas eficiências de remoção, no que diz respeito aos reatores 2 e 3. Notou-se que os valores de DQO efluente tenderam a uma estabilidade, ocorrência esta que difere dos valores de DQO afluente, observando uma diferença, fato este que deve-se a variabilidade das concentrações na entrada da estação de tratamento. Observou-se que não houve uma variação significante, tratando-se da eficiência dos reatores $2 \mathrm{e}$ 3. 


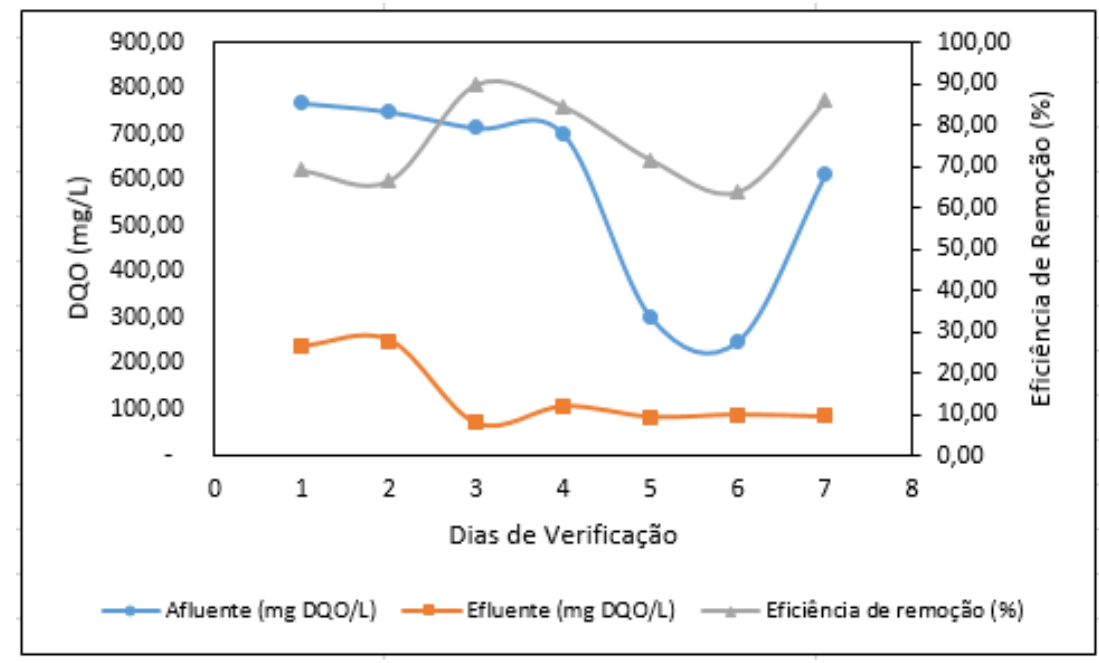

Figura 9 - llustração dos dados dos resultados de DQO afluente e efluente dos reatores 2 e 3

Tratando-se da carga de DQO que foi convertida em metano, em função da eficiência de remoção de carga orgânica, no reator 1, pode-se verificar que estas variáveis são diretamente proporcionais, quando observado o valor máximo e mínimo de 49,67 Kg DQO $\mathrm{CH}_{4} /$ dia e 6,20 $\mathrm{Kg}$ DQO $\mathrm{CH}_{4} /$ dia, respectivamente de carga de DQO convertida em metano, comparado ao valor máximo e mínimo de $94 \%$ e $64 \%$ da eficiência de remoção. Observou-se também que a produção do biogás, como também a produção de metano andam diretamente com a eficiência de remoção de carga orgânica, como também da carga de DQO convertida em metano. Verificou-se valor máximo e mínimo de 19,30 $\mathrm{m}^{3} / \mathrm{dia}$ e 2,40 m²/dia, respectivamente da produção volumétrica de metano. A Tabela 7 mostra os valores da carga e eficiência de DQO, bem como a produção do biogás, inclusive metano.

Tabela 7 - Valores máximos, mínimos, média aritmética e desvio padrão dos resultados calculados da carga de DQO e eficiência convertida em metano, como também a produção total do biogás e metano do reator 1

\begin{tabular}{c|c|c|c|c}
\hline Valores & $\begin{array}{c}\text { Carga de DQO } \\
\text { convertida em } \mathrm{CH}_{4} \\
\left(\mathrm{Kg} \mathrm{DQO} \mathrm{CH}_{4} / \mathrm{dia}\right)\end{array}$ & $\begin{array}{c}\text { Eficiência de } \\
\text { Conversão de DQO } \\
(\%)\end{array}$ & $\begin{array}{c}\text { Produção } \\
\text { volumétrica de } \mathrm{CH}_{4} \\
\left(\mathrm{~m}^{3} / \mathrm{dia}\right)\end{array}$ & $\begin{array}{c}\text { Produção de biogás } \\
\left(\mathrm{m}^{3} / \mathrm{dia}\right)\end{array}$ \\
\hline Máximo & 49,67 & 94,00 & 19,30 & 20,58 \\
Mínimo & 6,20 & 64,00 & 2,40 & 3,41 \\
Média & 22,77 & 76,88 & 8,84 & 11,01 \\
Desvio & 14,63 & 8,53 & 5,69 & 5,98 \\
Padrão & & & & \\
\hline
\end{tabular}


Tratando-se da carga de DQO que foi convertida em metano, em função da eficiência de remoção de carga orgânica, nos reatores 2 e 3, pode-se verificar que estas variáveis são diretamente proporcionais, quando observado o valor máximo e mínimo de 295,30 Kg DQO CH $4 /$ dia e 40,49 Kg DQO $\mathrm{CH}_{4} /$ dia, respectivamente de carga de DQO convertida em metano, comparado ao valor máximo e mínimo de $90 \%$ e $64 \%$ da eficiência de remoção. Observou-se também que a produção do biogás, como também a produção de metano andam diretamente com a eficiência de remoção de carga orgânica, como também da carga de DQO convertida em metano. Verificou-se valor máximo e mínimo de 115,11 $\mathrm{m}^{3} / \mathrm{dia}$ e 15,78 $\mathrm{m}^{3} / \mathrm{dia}$, respectivamente da produção volumétrica de metano. A Tabela 8 mostra os valores da carga e eficiência de $\mathrm{DQO}$, bem como a produção do biogás, inclusive metano.

Tabela 8 - Valores máximos, mínimos, média aritmética e desvio padrão dos resultados calculados da carga de DQO e eficiência convertida em metano, como também a produção total do biogás e metano dos reatores 2 e 3

\begin{tabular}{c|c|c|c|c}
\hline Valores & $\begin{array}{c}\text { Carga de DQO } \\
\text { convertida em } \mathrm{CH}_{4} \\
(\mathrm{Kg} \mathrm{DQO} \mathrm{CH} / \mathrm{dia})\end{array}$ & $\begin{array}{c}\text { Eficiência de } \\
\text { Conversão de DQO } \\
(\%)\end{array}$ & $\begin{array}{c}\text { Produção } \\
\text { volumétrica de } \mathrm{CH}_{4} \\
\left(\mathrm{~m}^{3} / \mathrm{dia}\right)\end{array}$ & $\begin{array}{c}\text { Produção de biogás } \\
\left(\mathrm{m}^{3} / \mathrm{dia}\right)\end{array}$ \\
\hline Máximo & 295,30 & 90,06 & 115,11 & 127,82 \\
Mínimo & 40,49 & 64,00 & 15,78 & 24,66 \\
Média & 166,91 & 76,02 & 65,08 & 82,83 \\
Desvio & 86,15 & 10,56 & 33,62 & 36,11 \\
Padrão & & & & \\
\hline
\end{tabular}

A Figura 10 ilustra o monitoramento dos resultados da produção do biogás e metano a partir da carga de DQO convertida em metano dos dados em função do $\mathrm{TDH}$, do reator 1. Verificou-se que a produção volumétrica de metano comportou-se inversamente ao TDH, ou seja, quanto maior o TDH menor a produção de metano. 


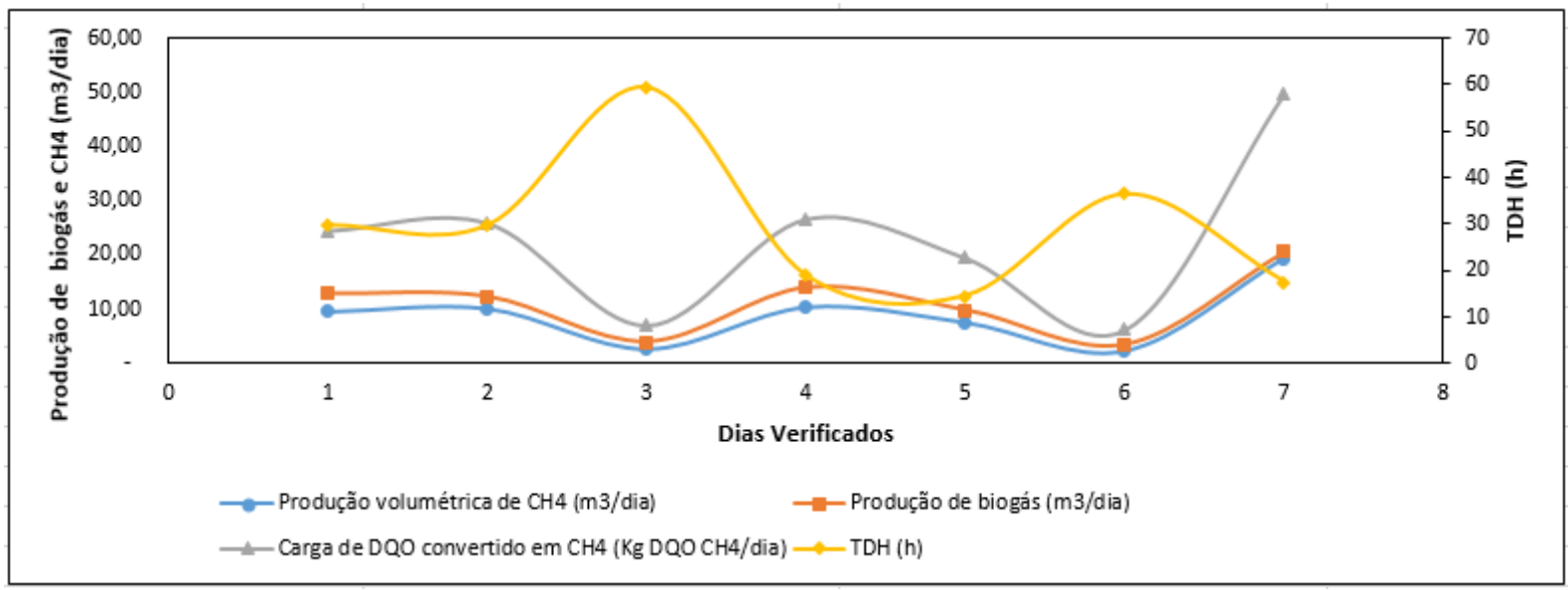

Figura 10 - llustração dos dados dos resultados da produção do biogás e metano a partir da carga de DQO convertida em metano em função do TDH do reator 1

A Figura 11 esboça o monitoramento dos resultados da produção do biogás e metano a partir da carga de DQO convertida em metano dos dados em função do $\mathrm{TDH}$, dos reatores 2 e 3 . Verificou-se que a produção volumétrica de metano comportou-se inversamente ao $\mathrm{TDH}$, ou seja, quanto maior o TDH menor a produção de metano.

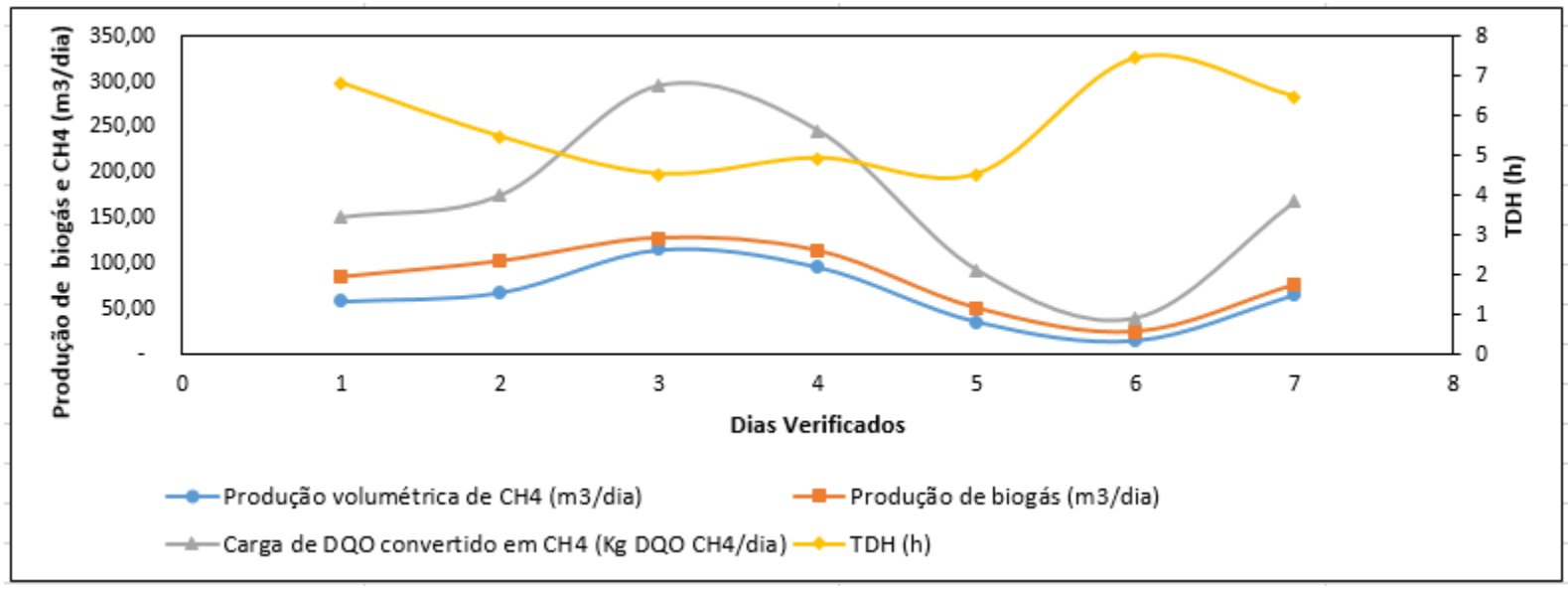

Figura 11 - llustração dos dados dos resultados da produção do biogás e metano a partir da carga de DQO convertida em metano em função do TDH dos reatores 2 e 3

Ciência e Sustentabilidade - CeS | Juazeiro do Norte v. 2, n. 1, p. 23-40, jan/jun 2016 


\title{
4 CONCLUSÃO
}

De acordo com as verificações, pode-se concluir que: No reator 1 observouse eficiência de $94 \%$ de remoção de matéria orgânica em termos de DQO, sendo convertida 49,67 Kg DQO CH $4 /$ dia, obtendo uma quantidade máxima de metano de 19,30 $\mathrm{m}^{3} / \mathrm{dia}$ em um TDH de 17,5 horas, a uma temperatura operacional de $30^{\circ} \mathrm{C}$. Nos reatores 2 e 3 observou-se eficiência de 90\% de remoção de matéria orgânica em termos de DQO, sendo convertida $295,30 \mathrm{Kg} \mathrm{DQO} \mathrm{CH}_{4} / \mathrm{dia}$, obtendo uma quantidade máxima de metano de 115,11 $\mathrm{m}^{3} / \mathrm{dia}$ em um TDH de 4,5 horas, a uma temperatura operacional de $31^{\circ} \mathrm{C}$.

Neste contexto, pode-se concluir que os resultados alcançados indicaram um potencial significativo de produção de metano a partir da remoção da carga orgânica, com possibilidades de aproveitamento energético a partir de uma fonte renovável.

\section{METHANE PRODUCTION FROM SEWAGE TREATMENT HEALTH IT'S SEEKING ALTERNATIVE ENERGY}

\begin{abstract}
We examined the methane production in two sewage treatment plants, composed of UASB reactors, in Ceará semiarid region. The process inside the reactor basically consists of an upward flow of sewage through a dense sludge bed and high activity effluent and collects at the top. On the reactor bottom there is the formation of a denser sludge bed to a more dispersed sludge near the top of the reactor. The stabilization of organic matter occurs through the passage and mixing of sewage in the sludge bed promoted by the upward flow and the formed gas bubbles. We used three reactors of UASB, full scale. The results showed that the reactor 1 had a $94 \%$ efficiency removal of organic matter in terms of COD, is converted $\mathrm{CH}_{4} 49.67 \mathrm{~kg} C O D$ / day, reaching a maximum quantity of methane $19,30 \mathrm{~m}^{3} /$ day at an HRT of 17.5 hours at an operating temperature of $30^{\circ} \mathrm{C}$. In reactors 2 and 3 observed efficiency of $90 \%$ removal of organic matter in terms of COD, is converted $\mathrm{CH}_{4} 295.30 \mathrm{~kg}$ COD/day, obtaining a maximum amount of methane $115.11 \mathrm{~m}^{3} /$ day at an HRT of 4.5 hours at an operating temperature of $31^{\circ} \mathrm{C}$. In this context, it can be concluded that the results obtained indicated a significant potential for methane production from the removal of organic matter, with energy recovery possibilities from a renewable source.
\end{abstract}

Keywords: UASB. Methane. Sewage. 


\section{REFERÊNCIAS}

CHERNICHARO, C. A. L. (2007). Reatores anaeróbios. Departamento de Engenharia Sanitária e Ambiental, UFMG, Belo Horizonte, Brasil, 246p.

COELHO, S. T.; VELÁZQUEZ, S. M. S. G.; SILVA, O. C da.; ABREU, F C de. (2006). Geração de energia elétrica a partir do biogás proveniente do tratamento de esgoto utilizando um grupo gerador de $18 \mathrm{~kW}$. Anais... V CONGRESSO BRASILEIRO DE PLANEJAMENTO ENERGÉTICO. Brasília, DF. $12 f$.

GARCIA, F. R. C. (2009). Avaliação do desempenho de um reator anaeróbio compartimentado no tratamento de soro de queijo. Dissertação (Mestrado em Engenharia e Ciência de Alimentos). Universidade Estadual Paulista "Julio de Mesquita Filho". São José do Rio Preto, SP. $103 f$.

LOBATO, L. C. da S. (2011). Aproveitamento energético de biogás gerado em reatores uasb tratando esgoto doméstico. Tese (Doutorado em Saneamento, Meio Ambiente e Recursos Hídricos). Universidade Federal de Minas Gerais. Belo Horizonte, MG. $187 f$.

RISSOLI, C. A. (2014). Estudo de parâmetros operacionais do reator UASB tratando esgoto doméstico e avaliação da biodegradabilidade do seu efluente. Dissertação (Mestrado em Tecnologia Ambiental e Recursos Hídricos). Universidade de Brasília. Brasília, DF. $143 f$.

SOARES, C. F. (2011). Análise da viabilidade do uso de biogás gerado em reator uasb para geração de energia elétrica. Monografia (Graduação em Engenharia Ambiental). Fundação Comunitária de Ensino Superior de Itabira. Itabira, MG. $65 f$.

VAN HAANDEL, A. C.; LETTINGA, G. (1994). Tratamento anaeróbio de esgoto. Um manual para regiões de clima quente. Universidade Federal da Paraíba, Campina Grande, PB, Brasil. 